\title{
Pregnancy after treatment with hydroxyurea in a patient with primary thrombocythaemia and a history of recurrent abortion
}

\author{
K I Cinkotai, P Wood, P Donnai, J Kendra
}

\begin{abstract}
A 28 year old patient with primary thrombocythaemia, who had had two stillbirths in the third trimester, is reported. She was successfully treated with hydroxyurea and delivered a healthy 6lb boy by elective caesarean section.

The ease with which this treatment can be given, its high level of tolerance among patients, and its low cost are likely to increase its use as a safe and effective treatment in pregnant patients with primary thrombocythaemia.
\end{abstract}

$(\mathcal{C}$ Clin Pathol 1994;47:769-770)

Primary thrombocythaemia is predominantly a disease of middle and old age in which the physical signs and symptoms result from a predisposition to both thrombosis and haemorrhage. Primary thrombocythaemia can also occur in a younger age group among whom pregnancies can be very difficult to manage. Despite this, most pregnancies lead to a successful conclusion. For those patients in whom treatment is felt to be indicated, options to date have consisted mainly of aspirin as an anti-thrombotic agent and plateletpheresis. Anti-proliferative agents, such as busulphan and interferons, have been little used due to the fear of potential teratogenesis, although evidence exists of their efficacy and safety in some patients. We describe a 28 year old patient with a history of two previous stillbirths in the third trimester, who was successfully treated with hydroxyurea, resulting in the delivery of a healthy $6 \mathrm{lb}$ boy by elective caesarean section.

Department of
Haematology,
Manchester Royal
Infirmary
K I Cinkotai
P Wood
Department of
Obstetrics and
Gynaecology, St
Mary's Hospital,
Manchester
P Donnai
Department of
Pathology, Burnley
General Hospital
J Kendra
Correspondence to:
Dr P Wood, Department of
Haematology, Hope
Hospital, Eccles Old Road,
Manchester, M6 8HD
Accepted for publication
9 February 1994

Case report

A 28 year old woman presented with a history of two unsuccessful pregnancies. The first pregnancy (December 1988) had resulted in the stillbirth of a $3 \mathrm{lb}$ boy at 29 weeks of gestation, the second (March 1990) in the emergency caesarean section at 33 weeks of a stillborn 4lb girl. On both occasions red cell transfusions were required for postpartum blood loss. Thrombocytosis had been documented in both of the previous pregnancies with a platelet count of 600-934 $\times 10^{9} / 1$. Treatment for the thrombocythaemia had not been given during either of these pregnancies. tion yielded normal results. A full blood count showed a haemoglobin of $127 \mathrm{~g} / 1$ white cells
On referral to our centre, physical examina- of $7.9 \times 10^{9} / 1$. (differential: neutrophils 5.6 $\times 10^{9} / 1$, lymphocytes $2.6 \times 10^{9} / 1$, monocytes $0.3 \times 10^{9} / 1$ ), and platelets $1341 \times 10^{9} / 1$. Bleeding time was prolonged at $6.5-11 \mathrm{~min}-$ utes (normal range one to six minutes). Platelet aggregation tests were abnormal (table). Bone marrow examination showed hypercellular particles with platelet clumping. Megakaryocytes were not increased in number but large hyperlobulated forms were noted. Iron stores were not reduced. A trephine biopsy specimen showed substantial increase in megakaryocyte numbers with atypia, consistent with essential thrombocytosis. Cytogenetic analysis showed a normal female karyotype. Our patient fulfilled those diagnostic criteria for primary thrombocythaemia suggested by the Polycythaemia Vera Study Group. ${ }^{1}$

As the predominant symptoms at presentation were related to a haemorrhagic rather than thrombotic tendency, treatment was begun with hydroxyurea 1-2 g daily in July 1990. A good response was obtained; the lowest platelet count was $295 \times 10^{9} / 1$ in December 1990. Following a full discussion of the associated risks and as a result of a planned pregnancy, the patient conceived in June 1991. Treatment was discontinued as soon as it was known she was pregnant at about six weeks gestation. Platelet aggregation tests two months later are shown in the table. Bleeding time was now normal (three to five minutes). Blood count at this stage showed a haemoglobin of $127 \mathrm{~g} / \mathrm{l}$, white cells of $6.7 \times 10^{9} / 1$ and a platelet count of $664 \times 10^{9} / 1$, and remained acceptable $\left(490-650 \times 10^{9} / 1\right)$ throughout the pregnancy.

In February 1992, after 35 weeks of an uncomplicated pregnancy, a healthy $6 \mathrm{lb}$ boy

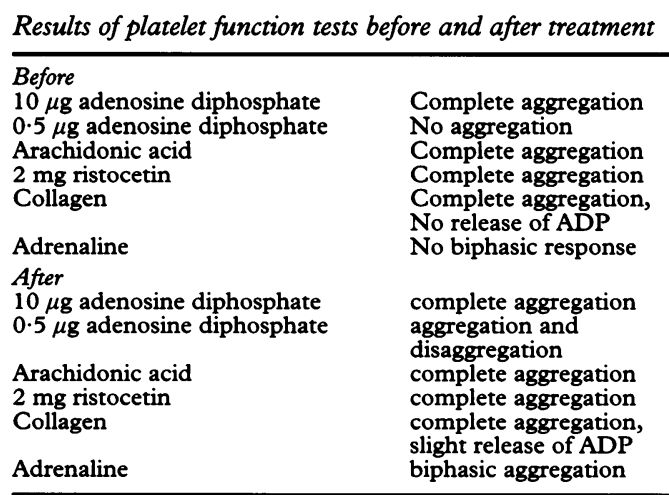


was born by elective caesarean section. At the time of delivery, blood count showed haemoglobin of $113 \mathrm{~g} / \mathrm{l}$, white cell count of $10.0 \times 10^{9} / 1$, and a platelet count of $357 \times 10^{9} / 1$. Treatment with hydroxyurea was started again (in March 1992) at $500 \mathrm{mg} /$ day when the platelet count rose to $716 \times 10^{\%} / 1$, and was continued at $1-2 \mathrm{~g}$ daily according to platelet count.

\section{Discussion}

A successful outcome to pregnancy was achieved in this patient, without complications. Despite a total of 12 months of treatment and the continued use of hydroxyurea until six weeks of gestation, no teratogenicity was observed. Platelet aggregation tests had substantially improved and good control of the platelet count was maintained for eight months despite the withdrawal of treatment. Subsequent re-introduction of hydroxyurea was required to control the platelet count.

The risks of thromboembolism and placental infarction in pregnancy are greatly enhanced in primary thrombocythaemia, but most pregnancies are successful. ${ }^{23}$ Treatment is generally advisable in those patients felt to be at high risk or with a previous history of affected pregnancies. The use of low dose aspirin should be the first choice, but some patients may have haemorrhagic problems or persistent thromboembolic phenomena despite this treatment. Alternative measures such as plateletpheresis may not be easily available or practicable at many centres and anti-proliferative agents are then advisable. The choice of such agents is complicated by the paucity of data on their use in this situation. Busulphan seems to have little teratogenic effect even in the first trimester, ${ }^{4}$ but long term lung toxicity and leukaemogenic effects are unacceptable. Interferons have been used successfully during pregnancy in chronic myelocytic leukaemia, but may still have teratogenic effects. ${ }^{5}$ Gamma-interferon seems to be teratogenic in mice and its safety in people remains uncertain. ${ }^{6}$
Hydroxyurea has now been well documented as permitting pregnancy during treatment for underlying myeloproliferative disorders, ${ }^{7-10}$ but we feel that in our patient the pregnancy resulted from an improvement in disease related placental insufficiency induced by treatment rather than merely an indirect absence of teratogenicity. The control of abnormal platelet numbers and function may have diminished the associated placental infarction or haemorrhage contributing to insufficiency of the materno-fetal placental circulation.

The optimal treatment during pregnancy has yet to be determined and further evaluation is critical. Good disease control before conception may minimise the risks to mother and fetus of both disease and treatment. Hydroxyurea seems to be the safest cytotoxic agent and successful pregnancies have been recorded despite both prolonged treatment and high doses. ${ }^{79} \mathrm{We}$ expect that the ease of administration, patient tolerability, and cost are likely to make this approach increasingly popular in the future.

1 Murphy S, Iland H, Rosenthal D, Laszio J. Essential thrombocythaemia: an interim report from the Polycythaemia Vera Study Group. Semin Hematol 1986;23:177-82

2 Beard J, Hillmen P, Anderson CC, Lewis SM, Pearson TC. Primary thrombocythaemia in pregnancy. $\mathrm{Br} \mathcal{F}$ Haematol 1991;77:371-4.

3 Mercer B, Drouin J, Jolly E, d'Anjou G. Primary thrombocythaemia in pregnancy: a report of two cases. thrombocythaemia in pregnancy: a rep

4 Williams DW. Busulphan in early pregnancy. Obstet Gynaecol 1966;27:738-40.

5 Baer MR, Ozer H, Foon KA. Interferon- $\alpha$ therapy during pregnancy in chronic myelogenous leukaemia and hairy cell leukaemia. Br $\mathcal{F}$ Haematol 1992;81:167-9.

6 Vassiliadis S, Athanassakis I. Type II interferon may be a potential hazardous therapeutic agent during pregnancy (letter). Br ₹ Haematol 1992;82:782-3.

7 Jackson N, Shukri A, Ali K. Hydroxyurea treatment for chronic myeloid leukaemia during pregnancy. $\mathrm{Br} \mathcal{F}$ Haematol 1993;85:203-4.

8 Delmier A, Rio B, Bauduer F, Ajchenbaum F, Marie J, Zittoun, R. Pregnancy during myelosuppressive treatment for chronic myelogenous leukaemia (letter). $\mathrm{Br} f$ ment for chronic myelog

9 Tertian G, Tchernia G, Papiernik E, Elefant E. Hydroxyurea and pregnancy. Am $\mathcal{f}$ Obstet Gynaecol 1992;166:1868.

10 Patel M, Dukes IAF, Hull JC. Use of hydroxyurea in chronic myeloid leukaemia during pregnancy: a case report. Am f Obstet Gynaecol 1991;165:565-6. 